\title{
Ontogeny of the Renin-Angiotensin-Aldosterone System in the Fetal and Newborn Lamb
}

\author{
SHARON R. SIEGEL AND DELBERT A. FISHER \\ Department of Pediatrics, Fetal-Maternal Research Labs, Los Angeles County Harbor-UCLA Medical Center, \\ Torrance, California, USA
}

\begin{abstract}
Summary
Thirteen chronic fetal lamb preparations between 95 and 142 days of gestation (term 145-150 days), and 10 newborn lambs were studied before and after the acute (1-2 min) infusion of furosemide ( $2 \mathrm{mg} / \mathrm{kg}$ ). The baseline to peak plasma renin activity (PRA) response to furosemide increased from $\Delta 3.0 \pm 1.3 \mathrm{ng} / \mathrm{ml} / \mathrm{hr}(\mathrm{M}$ and SEM) and 95-106 days of gestation to $\Delta 18.4 \pm 4.0(P<$ $0.01)$ at 123-142 days and $\Delta 33.6 \pm 6.5(P<0.001)$ in the newborn. Baseline plasma aldosterone concentrations were similar in the fetus and pregnant ewe; aldosterone levels were higher in the newborn lamb than in the nonpregnant ewe. The newborn plasma aldosterone response to furosemide via the endogenous reninangiotensin system was $\Delta 17.1 \pm 4.2 \mathrm{ng} / \mathrm{dl}(P<0.01)$; the fetal lamb plasma aldosterone level did not increase. The results indicate that the renin-angiotensin system cannot be stimulated by furosemide under $\mathbf{1 0 6}$ days of gestation; the response after $\mathbf{1 1 0}$ days increases with gestational age. Aldosterone concentrations in the fetal lamb are probably maintained primarily by the pregnant ewe and do not increase in response to endogenous renin stimulation as in the newborn.
\end{abstract}

\section{Speculation}

Fetal renin responsiveness increases with gestational age, while fetal aldosterone secretion is unresponsive to stimulation by the renin-angiotensin system. Therefore, the fetal adrenal cortex is the limiting factor in the pituitary-renal-adrenal axis before term.

The newborn lamb has high baseline PRA and aldosterone concentrations (15), and the renin-angiotensin-aldosterone system responds promptly to stimulation by furosemide in the newborn lamb. The renin-angiotensin system in the chronic fetal lamb preparation after 110 days of gestation responds to stimulation by furosemide (18) blood volume reduction $(13,17)$ or aortic constriction (17). Alexander et al. (1) were unable to increase fetal plasma aldosterone levels in three acute fetal sheep preparations by ACTH or exogenous angiotensin II infusion and were unable to depress plasma aldosterone with dexamethasone. Although the acute fetal sheep preparation is stressed by surgery, these results suggest that the fetal lamb adrenal gland is unresponsive to aldosterone stimulation or suppression, while the kidney is capable of renin secretion. The present study was conducted to determine in the chronic nonstressed fetal sheep preparation 1) the pattern of baseline PRA and aldosterone levels during the last trimester, and 2) when the system components will respond to stimulation.

\section{MATERIALS AND METHODS}

Thirteen chronically catheterized fetal lamb preparations between 95 days of gestation and term and 10 newborn lambs less than 1 wk of age were studied. Pregnant ewes were obtained from a local source and maintained in the vivarium before surgery. Rompun (0.1-0.2 ml), a tranquilizer, was administered to the ewe before uterotomy and fetal catheterization; epidural anesthesia ( 5 $\mathrm{ml}$ of $2 \%$ xylocaine) was employed for the surgical procedure. The uterus was exposed through a small midline abdominal incision and the head delivered through a small hysterotomy. Carotid arterial and jugular venous polyvinyl catheters were placed. The fetus was returned to the uterine cavity and the uterine incision closed. The catheters were brought out through skin tunnels in the lateral abdominal wall and secured in a pouch attached to the back of the ewe. The animals were maintained on ampicillin for 5 days postoperatively and then studied. Carotid arterial and jugular venous catheters were placed in the newborn under local anesthetic (xylocaine). The animal was returned to the mother and studied 4-5 days later. The newborn animals were restrained in a supine position on a specially constructed board so that they are nonstressed. They were kept warm, and were quiet or asleep during the study.

After a 30-min control period, furosemide $(2 \mathrm{mg} / \mathrm{kg})$ was infused over 1-2 min. Blood samples for PRA, plasma aldosterone, plasma sodium $(\mathrm{Na})$, and blood hematocrit were drawn $10 \mathrm{~min}$ before and 8,20,35, and $65 \mathrm{~min}$ after the furosemide infusion. Exogenous angiotensin II $(0.25 \mu \mathrm{g} / \mathrm{kg} / \mathrm{min})$ was infused continuously for $30 \mathrm{~min}$ in three fetal lambs from 117-138 days of gestation. PRA $(6,14)$ and aldosterone (7) were measured by radioimmunoassay. The coefficient of intraassay variation was $8 \%$ and interassay variation $10 \%$. The cross reaction of aldosterone was $0.5 \%$ with 11 -desoxycortisol and $2 \%$ with cortisol at 20,000 $\mathrm{pg} / \mathrm{ml}$. The sensitivity was $0.67 \pm 0.14 \mathrm{ng} / \mathrm{dl}(\mathrm{M}$ and SEM). Sodium was measured by flame photometry. Blood pressure was monitored continuously in the 10 newborn and seven of the fetal lambs via pressure transducers and recorded on a Gould recorder. Comparisons of the dose response changes for each animal were calculated by $t$ test. The mean change for one fetal age group was compared to the mean change in the other fetal and newborn age groups.

\section{RESULTS}

Figures 1 and 2 show the circulating PRA and aldosterone levels in the fetal and newborn lamb, and in the pregnant and nonpregnant ewes. The $N$ values represent the number of samples. Baseline PRA increased from $4.9 \pm 0.8 \mathrm{ng} / \mathrm{ml} / \mathrm{hr}$ (M and SEM) between 95-124 days of gestation to $12.6 \pm 2.5(P<0.01)$ between 125-149 days of gestation. PRA in the newborn lamb, $21.5 \pm 2$ $\mathrm{ng} / \mathrm{ml} / \mathrm{hr}$ was greater than in the fetal lamb after 125 days of gestation $(P<0.02)$. Baseline PRA in the pregnant ewe increased from $2.6 \pm 0.3 \mathrm{ng} / \mathrm{ml} / \mathrm{hr}$ before 124 days of gestation to $5.2 \pm 0.8$ $(P<0.02)$ after 125 days of gestation, both these values were significantly lower than the respective levels in fetal lambs $(P<$ 0.05 and $P<0.01$ ).

Fetal plasma aldosterone concentrations, Figure 2, increased from $4.1 \pm 0.5 \mathrm{ng} / \mathrm{dl}$ between $95-124$ days of gestation to $8.1 \pm$ 0.9 between $125-149$ days of gestation. These concentrations were statistically similar to respective values in the pregnant ewes. Baseline aldosterone levels $(11.8 \pm 2.0 \mathrm{ng} / \mathrm{dl})$ were higher in the 


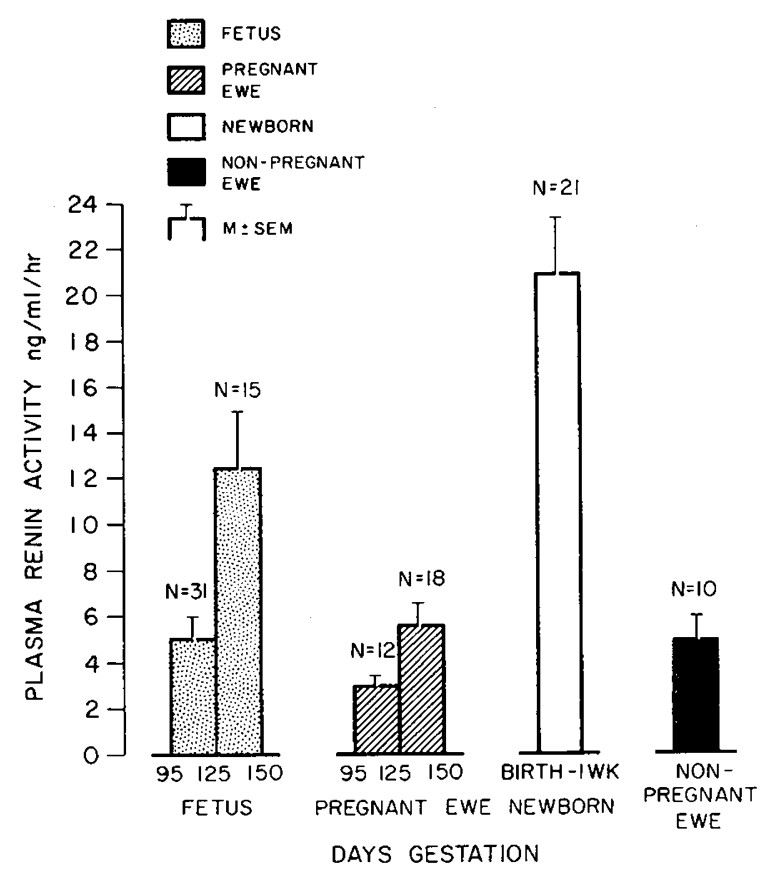

Fig. 1. Baseline PRA levels in the fetal and newborn lamb and in the pregnant and nonpregnant ewe.

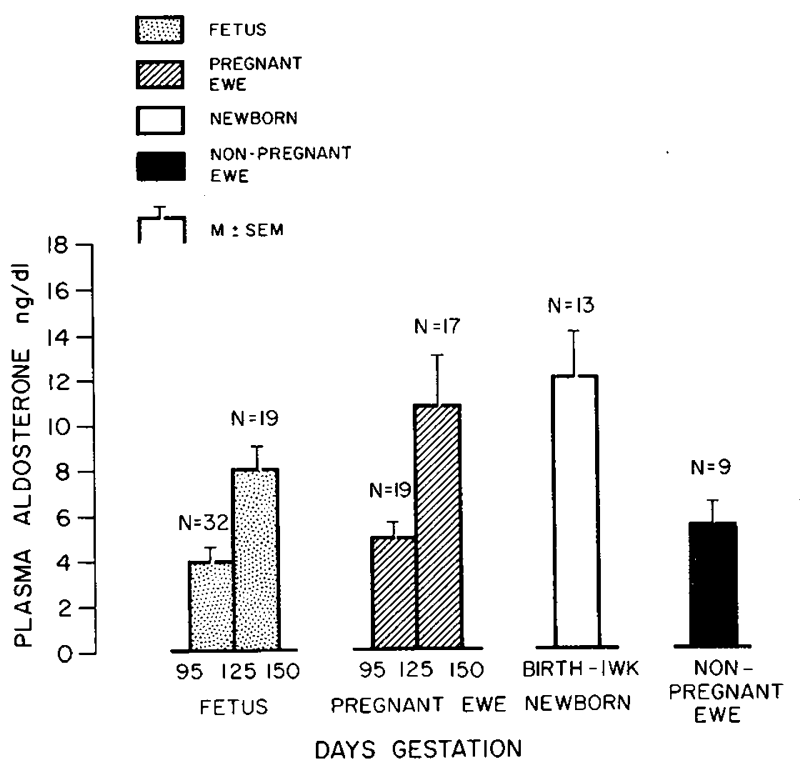

Fig. 2. Baseline plasma aldosterone levels in the fetal and newborn lamb, and in the pregnant and nonpregnant ewe.

newborn lambs than in the nonpregnant ewe $(5.5 \pm 1.1, P<0.02)$. Fetal plasma sodium levels increased from $139 \pm 1.7 \mathrm{mEq} /$ liter between 95-124 days of gestation to $146 \pm 2.3$ between 125-149 days of gestation $(P<0.02)$.

Figure 3 shows the PRA response to furosemide between 95 days of gestation and term in the fetal lamb and in the newborn lamb. Between 95-106 days of gestation $(N=6)$, PRA changed from a baseline of $7.21 \pm 0.85 \mathrm{ng} / \mathrm{ml} / \mathrm{hr}$ to $9.21 \pm 1.84$ at $20 \mathrm{~min}$ and remained at this level throughout the 65 -min study period. The PRA response to furosemide was not statistically significant. Between 124 days of gestation and term $(\mathrm{N}=7)$, PRA increased from a baseline of $15.5 \pm 3.0 \mathrm{ng} / \mathrm{ml} / \mathrm{hr}$ to $19.5 \pm 4.1$ at $8 \mathrm{~min}$ post furosemide $(P<0.05), 23.9 \pm 4.9$ at $20 \mathrm{~min}(P<0.01)$ and remained high throughout the $65 \mathrm{~min}$. PRA increased in the newborn lamb $(\mathrm{N}=10)$ from a baseline of $20.3 \pm 3.3 \mathrm{ng} / \mathrm{ml} / \mathrm{hr}$ to $39.4 \pm 8.2$ at $8 \mathrm{~min}$ post furosemide $(P<0.01)$ and remained high through $65 \mathrm{~min}$.
Figure 4 shows the aldosterone response to furosemide. Between 95-106 days of gestation $(\mathrm{N}=6)$ the plasma aldosterone level remained at a baseline of $4.0 \pm 0.5 \mathrm{ng} / \mathrm{dl}$ throughout the $65-\mathrm{min}$ study period. Between 124 days of gestation and term the aldosterone baseline level was $6.1 \pm 1.1 \mathrm{ng} / \mathrm{dl}$. The highest level, $8.0 \pm$ $2.2 \mathrm{ng} / \mathrm{dl}$ at $65 \mathrm{~min}$ post furosemide, was not statistically different. In the newborn lambs, baseline aldosterone increased from 12.8 $\pm 2.5 \mathrm{ng} / \mathrm{dl}$ to $22.9 \pm 7.7(P<0.05)$ at $35 \mathrm{~min}$ and $22.9 \pm 4.4(P$ $<0.01)$ at $65 \mathrm{~min}$ post furosemide.

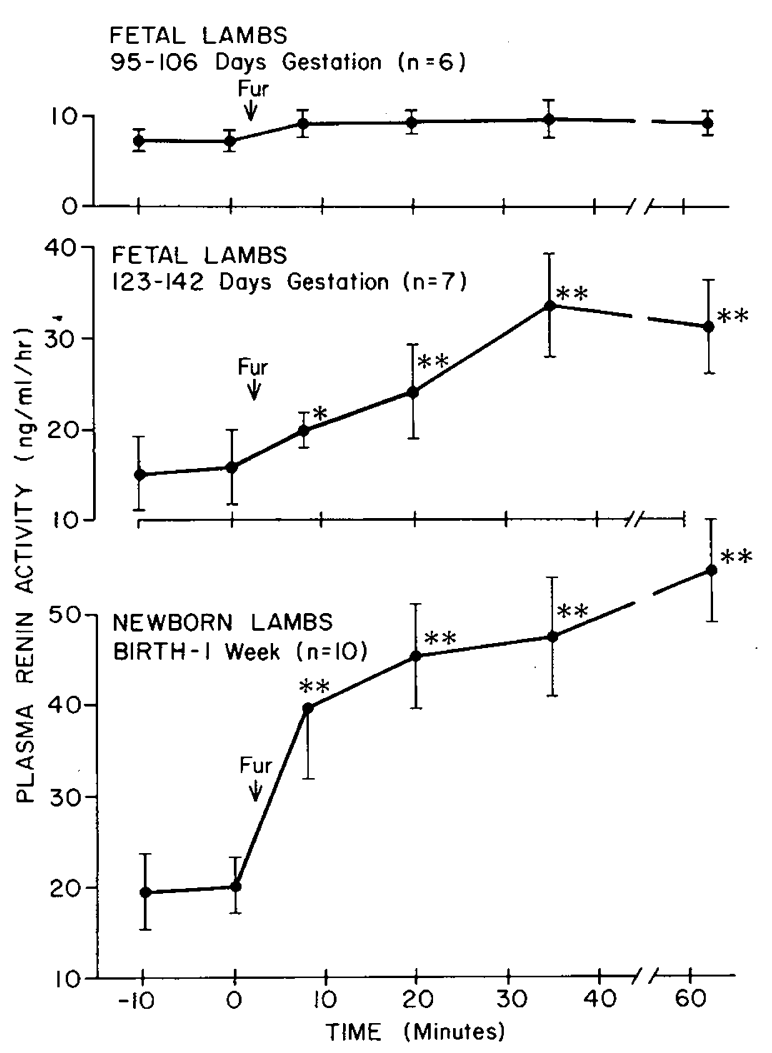

Fig. 3. The PRA response to furosemide in the fetal and newborn lamb $\left({ }^{*} P<0.05\right)\left({ }^{* *} P<0.01\right)\left({ }^{* * *} P<0.001\right)$.

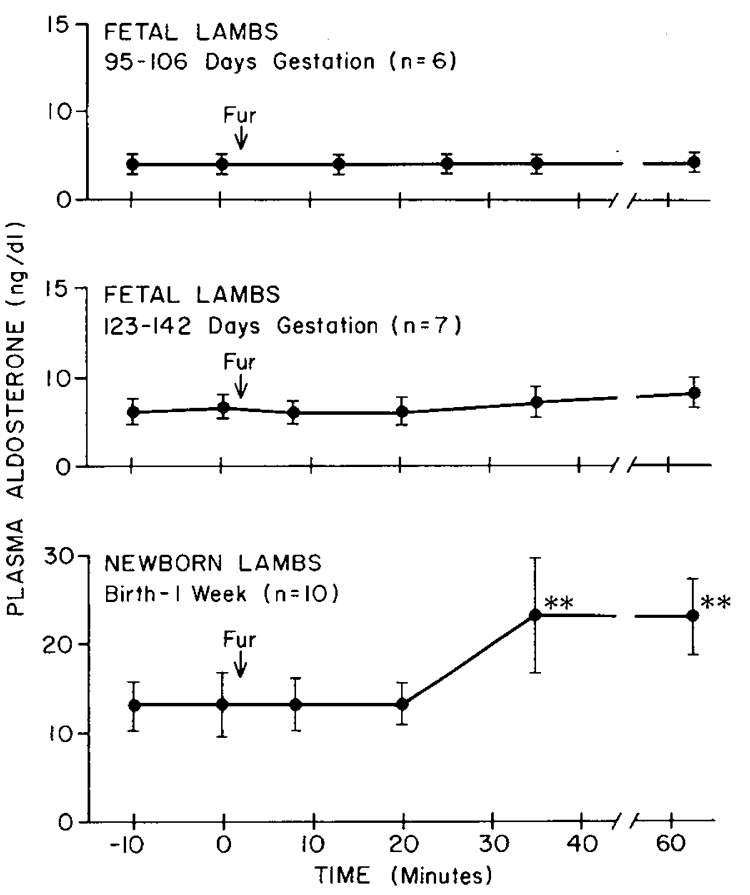

Fig. 4. The plasma aldosterone response to furosemide in the fetal and newborn lamb $\left({ }^{*} P<0.05\right)$. 
Table 1 shows the baseline to peak PRA and aldosterone responses to furosemide. PRA increased from $\Delta 3.0 \pm 1.3 \mathrm{ng} / \mathrm{ml} /$ hr between $95-106$ days of gestation to $\Delta 18.4 \pm 4.0(P<0.01)$ between 123-142 days of gestation and to $\Delta 33.6 \pm 6.5$ in the newborn $(P<0.001)$. Plasma aldosterone was $\Delta 0$ between $95-$ 106 days of gestation, $\Delta 2.1 \pm 1.0 \mathrm{ng} / \mathrm{dl}$ between $123-142$ days of gestation and $\Delta 17.1 \pm 4.2$ in the newborn $(P<0.001)$. The mean systemic blood pressure started to fall at $20 \mathrm{~min}$ post furosemide and decreased a $\mathrm{M}$ and SEM of $5 \pm 1.0 \mathrm{~mm} \mathrm{Hg}$ by $35 \mathrm{~min}$ in the 10 newborn lambs $(P<0.05)$ and two of seven fetal lambs monitored continuously. Amniotic pressures were not monitored in the fetal lambs. Plasma sodium concentration and blood hematocrit did not change throughout the furosemide study period.

Exogenous angiotensin II $(0.25 \mu / \mathrm{kg} / \mathrm{min})$ infused continuously for $30 \mathrm{~min}$ raised the mean systemic blood pressure $14.3 \pm 1.9$ $\mathrm{mm} \mathrm{Hg}$. Plasma aldosterone levels drawn at 5, 30, and $60 \mathrm{~min}$ after the start of the infusion did not change from the baseline level of $3.0 \pm 0.5 \mathrm{ng} / \mathrm{dl}$.

\section{DISCUSSION}

PRA (Fig. 1) levels in the fetal lamb are low before 124 days of gestation $(4.9 \pm 20.8 \mathrm{ng} / \mathrm{ml} / \mathrm{hr}, \mathrm{M}$ and SEM) compared to values in the newborn $(21.5 \pm 2.0 \mathrm{ng} / \mathrm{ml} / \mathrm{hr}$.). Although the PRA levels $(12.6 \pm 2.5 \mathrm{ng} / \mathrm{ml} / \mathrm{hr})$ between 125 days of gestation and term were high compared to the pregnant ewe $(P<0.01)$, they were lower than values in the newborn lambs $(P<0.02)$. Respective fetal plasma aldosterone levels (Fig. 2) increased after 125 days of gestation, but were similar to the paired values in the pregnant ewes. These results suggest that fetal lamb plasma aldosterone levels are maintained via placental transfer from the pregnant ewe before term. Pasqualini et al. (10) have documented the placental transfer of aldosterone from mother to fetus in the guinea pig. Bayard et al. (2) demonstrated that aldosterone crossed the placenta in the human at the time of Caesarean section; the fetal levels (2) were 2 to 12-times higher than the maternal levels, showing that the human fetus secreted aldosterone at the time of birth. Alexander et al. (1) has reported that cortisol, corticosterone, and aldosterone secretion rates were greatly increased toward term and after birth in the sheep.

The newborn systemic blood pressure started to drop at $20 \mathrm{~min}$ post furosemide and decreased $5 \pm 1 \mathrm{~mm} \mathrm{Hg}(\mathrm{M} \pm \mathrm{SEM})$ by 35 min post furosemide. The blood pressure changes were unrelated to the PRA elevation which occurred at $8 \mathrm{~min}$ postfurosemide $(P$ $<0.01)$ in the 10 newborn and $20 \mathrm{~min}$ in the fetal lambs $(P<$ $0.01)$. Fetal amniotic pressure was not monitored in this study. Although a change in amniotic pressure can effect the recorded fetal systemic pressure, the amniotic pressure is low $(<12 \mathrm{~mm}$ $\mathrm{Hg}$ ) and unlikely to obscure a systemic pressure related PRA change in the fetal lamb. There was no change in plasma sodium or hematocrit during the furosemide study period. The mechanism by which furosemide stimulates renin release has not been clarified. Previous studies have shown that the maintenance of sodium and water balance by continuous replacement of urinary losses with isotonic saline in dogs (19) or by shunting of urine into the femoral vein in rabbits (8) will not alter the furosemide-induced renin secretion, despite the constancy of blood pressure, plasma sodium concentration, and plasma volume. The early PRA response at $8 \mathrm{~min}$ post furosemide in the fetal and newborn lambs might have mediated by alterations in intrarenal hemodynamics, by increase in intratubular sodium in the region of the macula densa, or by direct inhibition of macula densa sodium transport. It has been shown that furosemide in low doses does not significantly alter glomerular filtration (19) or renal plasma flow. In high doses $(2.5 \mathrm{mg} / \mathrm{kg})$ renal plasma flow increases. The drug increases blood flow to the pars radiata of the kidney cortex and decreases flow to the juxtaglomerular cortex and medulla (4). Because most renal renin resides in the outer cortex, these data suggest that altered renal hemodynamics may not evoke the early renin release. Vander and Miller (20) and White (21) showed that increasing the tubular load resulted in reduction of the secretion of renin induced by clamping the renal artery. A direct inhibitory effect on macula densa sodium transport thus seems likely. The present data do not clarify the mechanism further.

Furosemide in the present studies did not stimulate fetal renin secretion (Fig. 3, Table 1) under 106 days of gestation, and the baseline to peak PRA response increased with gestational age through the newborn period $(\Delta 18.4 \pm 4.0$ at 123-142 days of gestation, $P<0.01$, and $\Delta 33.6 \pm 6.5$ in the newborn, $P<0.001$ ). Physiologic immaturity at the renal tubular juxtaglomerular level may be responsible for the lack of response under 106 days of gestation. Anatomic maturity of bowie positive granular cells (renin cells) which are similar to adult granular cells are present at 96 days of gestation (17).

Plasma aldosterone levels did not increase in response to furosemide (Fig. 4) in the fetal lamb; however, there was a response in the newborn lamb, in agreement with earlier reports (15). Fetal plasma angiotensin II levels have been shown to increase in response to renin (13). Angiotensin II levels also have been shown to increase in response to hypoxemia (13) or hemorrhage (12). The hypertensive dose of exogenous angiotensin II did not stimulate aldosterone secretion in the three fetal lambs between 117-138 days of gestation. Therefore, the possibility that insufficient endogenous angiotensin II levels were present to stimulate aldosterone secretion in the furosemide experiments is unlikely. These data show that the fetal renin-angiotensin system is functional during the third trimester but does not stimulate aldosterone before term. Therefore, the renin-angiotensin-aldosterone system does not appear to play a major role in fetal salt and water balance before parturition. Because sodium and water cross the placenta, salt and water balance can be maintained by the pregnant mother. Beitins et al. (3) found that infants of mothers on a low sodium diet or diuretic medication had higher cord blood and postnatal plasma aldosterone concentrations than control infants, suggesting that aldosterone can be stimulated during parturition.

Fetal PRA levels increased after 125 days of gestation and were higher than in the pregnant ewe. The reason for these high levels and the significance of the fetal renin-angiotensin system in fetal cardiovascular homeostasis and the control of fetal-placental blood volume is not known. Plasma sodium levels in the fetus increased after 125 days of gestation; and this increase would tend to suppress rather than stimulate renin secretion. The lack of aldosterone response to stimulation by the renin-angiotensin system in the fetus (Fig. 4) would prevent negative feedback suppression of renin at the kidney level. The renin-angiotensin-aldosterone system is intact in the newborn lamb $(15,16)$. The low arterial blood pressure, decreased circumferential tension of the small vessels and/or decreased vascular vasoconstrictor sensitivity may be responsible for the high PRA levels in the fetus from 125

Table 1. The PRA and aldosterone response to furosemide in the fetal and newborn lamb ${ }^{1}$

\begin{tabular}{lccc}
\hline & \multicolumn{3}{c}{ Baseline to peak response } \\
\cline { 2 - 4 } Gestational age & $95-106$ days & $123-142$ days & Newborn, birth-1 wk \\
\hline PRA (ng/ml/hr) & $\Delta 3.0 \pm 1.3$ & $\Delta 18.4^{2} \pm 4.0 \downarrow$ & $\Delta 33.6 \pm 6.5^{3}$ \\
Plasma aldosterone (ng/d) & 0 & $\Delta 2.1 \pm 1.0$ & $\Delta 17.1 \pm 4.2^{3}$ \\
\hline
\end{tabular}

\footnotetext{
${ }^{1} M$ and SEM.

${ }^{2} P<0.01$.
}

${ }^{3} P<0.001$. 
days to term. The increase of fetal plasma renin induced by small (3\% blood volume) hemorrhage $(13,17)$, the reduction in PRA by expansion of fetal blood volume (9), the rise in blood pressure in response to exogenous angiotensin II (30 ng/kg/body wt.) (11), and the in vitro umbilical artery constriction observed in response to low concentrations of angiotensin II (5) suggest that the fetal renin-angiotensin may play an important role in maintenance of blood pressure and/or distribution of fetoplacental blood volume. The authors have recently shown that the renin-angiotensin system is maintaining newborn blood pressure (16). The role of the high PRA and aldosterone levels in the newborn have been discussed elsewhere (15).

\section{CONCLUSION}

Furosemide stimulated the renin-angiotensin system in the fetal lamb after 110 days of gestation, but there was no aldosterone response. The renin-angiotensin system and aldosterone were stimulated by furosemide in the newborn lamb. PRA resting levels increased after 125 days of gestation and were highest in the newborn. Fetal aldosterone levels were similar to maternal values, suggesting that the primary maintenance of aldosterone levels and control of salt and water balance is by the pregnant ewe. The reason for the lack of renin stimulation under 106 days of gestation is unknown.

\section{REFERENCES AND NOTES}

1. Alexander, D. P., Britton, H. G., James, V. H. T., Nixon, D. A., Parker, R. A., Wintour, E. M., and Wright, R. D.: Steroid secretion by the adrenal gland of foetal and neonatal sheep. J. Endocrinol., 40: 1 (1968).

2. Bayard, F., Ances, I. G., Tapper, A. J., Weldon, V. V., Kowarski, A., and Migeon, C. J.: Transplacental passage and fetal secretion of aldosterone. J. Clin. Invest, 49: 1389 (1970).

3. Beitins, I. A., Bayard, F., Levitsky, L., Ances, I. G., Kowarski, A., and Migeon, C. J.: Plasma aldosterone concentration at delivery and during the newborn period. J. Clin. Invest., 51: 386 (1972).

4. Birtch, A. G., Zakhein, R. M., Jones, L. B., and Barger, A. C.: Redistribution of renal blood flow produced by furosemide and ethacrynic acid. Circ. Res., 21. 869 (1967).

5. Dyer, D. C.: Effects of metabolic inhibitors on responses to seratonin and angiotensin on isolated sheep umbilical arteries. Eur. J. Pharmacol., 16: 357 (1971).
6. Haber, E., Koerner, T., Page, L. B., Kliman, B., and Purnode, A.: Application of a radioimmunoassay for angiotensin $I$ in normal human subjects. J. Clin. Endocrinol. Metab., 29: 1349, (1969).

7. Ito, T., Woo, J., Hening, R., and Horton, R.: A radioimmunoassay for aldosterone in human peripheral plasma including a comparison of alternate techniques. J. Clin. Endocrinol. Metab., 34: 106 (1972).

8. Meyer, P., Menard, J., Papanicolaou, N., Alexander, J. M., Devaux, C., and Milliez, P.: Mechanism of renin release following furosemide diuresis in rabbits. Am. J. Physiol., 215: 908 (1968).

9. Mott, J. C.: Place of the renin-angiotensin system before and after birth. Br. Med. Bull., 3I: 44 (1975).

10. Pasqualini, S. R., Sumida, C., and Gelly, C.: Steroid hormone receptors in fetal guinea-pig kidney. J. Steroid Biochem., 5: 977 (1974).

11. Pipkin, F. B.: Circulating vasoactive hormones in immature mammals. (Thesis for D. Phil. degree) Univ. of Oxford.

12. Pipkin, F. B., Kirkpatrick, S. M. L., Lumbers, E. R., and Mott, J. C.: Renin and angiotensin levels in foetal, newborn, and adult sheep. J. Physiol. (Lond.), 241 : 575 (I974a)

13. Pipkin, F. B., Lumbers, E. R., and Mott, J. C.: Factors influencing plasma renin and angiotensin $\mathrm{II}$ in the conscious pregnant ewe and its foetus. J. Physiol. (Lond), 243: 619 (1974b).

14. Radioimmunology Manual, 3rd Edition, p. 76 (Nichols Institute of Endocrinology, San Pedro, CA, 1976).

15. Siegel, S. R., and Fisher, D. A.: The renin-angiotensin-aldosterone system in the newborn lamb: response to furosemide. Pediatr. Res., 11: 837 (1977).

16. Siegel, S. R., and Fisher, D. A.: The effects of angiotensin II blockade and nephrectomy on the renin-angiotensin system in the newborn lamb. Pediatr. Res., 13: 603 (1979).

17. Smith, F. G., Jr., Lupu, A. N., Barajas, L., Bauer, R., and Bashore, R. A.: The renin angiotensin system in the fetal lamb. Pediatr. Res., 8: 611 (1974).

18. Trimper, C. E., and Lumbers, E. R.: The renin-angiotensin system in foetal lambs. Pflugers Arch. (Eur. J. Physiol.), 336: 1 (1972).

19. Vander, A. J., and Carlson, J.: Mechanism of the effects of furosemide on renin secretion in anesthetized dogs. Circ. Res., 25: 145 (1969).

20. Vander, A. J., and Miller, R.: Control of renin secretion in the anesthetized dog. Am. J. Physiol., 207: 537 (1964).

21. White, R. N.: Control of renin secretion in the dog. Circulation, 32: (Suppl. 2) 219 (1965).

22. This research was supported by grant 5 RO1 HD 10611-02 from the National Institutes of Child Health and Human Development, National Institutes of Health, Bethesda, MD, USA.

23. Requests for reprints should be addressed to: S. R. Siegel, M. D., L. A. County Harbor-UCLA Medical Center, Bldg. A-17, 1000 West Carson Street, Torrance, CA 90509.

24. Received for publication September 25, 1978.

25. Accepted for publication March 2, 1979. 